\title{
ARTICLE OPEN \\ Frequency of severe thunderstorms across Europe expected to increase in the 21 st century due to rising instability
}

\author{
Anja T. Rädler $\mathbb{D}^{1,2}$, Pieter H. Groenemeijer ${ }^{2}$, Eberhard Faust ${ }^{1}$, Robert Sausen ${ }^{3}$ and Tomáš Púčik ${ }^{2}$
}

We show that the frequency of damaging convective weather events including lightning, hail and severe wind gusts will likely increase over Europe until the end of this century. We apply a set of additive regression models to an ensemble of 14 regional climate simulations and find that convective instability will increase as a result of rising humidity near the earth's surface. Even though a slight decrease in thunderstorm occurrence in southwestern and southeastern Europe is projected, the probability of severe weather will increase throughout Europe, in particular for very large hail. It might be expected that Arctic amplification would lead to a weaker jet stream and, thus lower vertical wind shear, but we find instead that the jet changes little or even increases in situations with convective instability. To cope with the rising hazard probabilities, risk models will need to be adapted, while investment in sturdier structures, like the use of hardened glass in greenhouses or solar panels, will become more costeffective. Furthermore, the need will grow to advise the public on loss prevention by taking precautionary measures as storms approach.

npj Climate and Atmospheric Science (2019)2:30; https://doi.org/10.1038/s41612-019-0083-7

\section{INTRODUCTION}

Severe weather related to mid-latitude convective storms, such as hail, tornadoes, and damaging wind gusts, constitute a sizable and increasing fraction of all weather-related economic losses. ${ }^{1}$ In convective storms, large amounts of buoyant air quickly move upward, leading to rapid condensation of the contained water vapor, releasing latent heat in the storm's updraft. Environmental vertical wind shear can further enhance the intensity and longevity of individual thunderstorms by promoting their organization, for example, into rotating supercells or into bowechoes, coined in reference to their representation on weather radar. $^{2-4}$ Such well-organized storms are the most prolific producers of convective severe weather.

Anthropogenic climate change is associated with a multitude of changes in the troposphere, which, apart from a globally rising temperature, includes widespread increases of water vapor content in the lowest layers of air, while changes of midtropospheric humidity-both increases and decreases-occur as well. Furthermore, evidence is mounting that the polar jet stream has begun to meander more as a result of arctic amplification., ${ }^{5,6}$

Such changes will affect the severity and frequency of convective storms. For instance, higher low-level water vapor content amplifies convective instability, and hence, updraft intensity, while lower mid-tropospheric humidity would suppress storm initiation, even in the presence of adequate instability. ${ }^{7}$ Moreover, the speed of the jet stream is strongly tied to vertical wind shear, with which convective storms interact. Therefore, the question arises what the implications are of projected changes in these environmental constraints on the occurrence of convective hazards.

Previous studies have explored this question for Europe ${ }^{8}$ and the United States ${ }^{9,10}$ by counting how often proxy variables for convective instability, wind shear, and storm probability would simultaneously exceed certain threshold values. Studies using global and regional climate models have demonstrated that, until the end of the century, favorable conditions for severe storms should become more frequent across much of the USA, ${ }^{9,10}$ large parts of Europe, ${ }^{8}$ and Australia. ${ }^{11}$ Yet, quantitative projections distinguishing between the various severe storm hazards and different intensities, such as hail size, have not been constructed. Furthermore, these studies have used a binary threshold approach that oversimplifies the relation between predictors and hazard probability.

\section{RESULTS AND DISCUSSION}

Here we have used a set of additive regression convective hazard models (AR-CHaMo), based on lightning detection data, hazard observations, and reanalysis data, ${ }^{7}$ that assign a hazard probability to any location for any 6-hourly time period. AR-CHaMo considers separately the probability of lightning (i.e., thunderstorm occurrence) and that of hazard occurrence given that lightning occurs. This allows one to monitor the evolution of the fraction of storms that produce a hazard, which can be called the "severe weather efficiency." We applied the regression models to future projections until 2100 of an ensemble of 14 regional climate models (EUROCORDEX ${ }^{12}$ ) to assess the effects of anthropogenic climate change on the frequency of lightning, large hail, and convective winds in two climate scenarios ${ }^{13}$ (RCP4.5 and RCP8.5).

The simulated annual number of 6-hourly periods with lightning (hereafter lightning frequency) in the historical (1971-2000) reference period is highest in central and southern Europe, particularly over mountain ranges (Fig. 1a). This pattern corresponds well to that observed by lightning detection networks. ${ }^{7}$ By

\footnotetext{
${ }^{1}$ Munich Re, Munich, Germany; ${ }^{2}$ European Severe Storms Laboratory, Wessling, Germany and ${ }^{3}$ Deutsches Zentrum für Luft und Raumfahrt (DLR), Institut für Physik der Atmosphäre, Oberpfaffenhofen, Germany

Correspondence: Anja T. Rädler (anja@raedler.online) or Pieter H. Groenemeijer (pieter.groenemeijer@essl.org)
}

Received: 11 February 2019 Accepted: 15 July 2019

Published online: 27 August 2019 

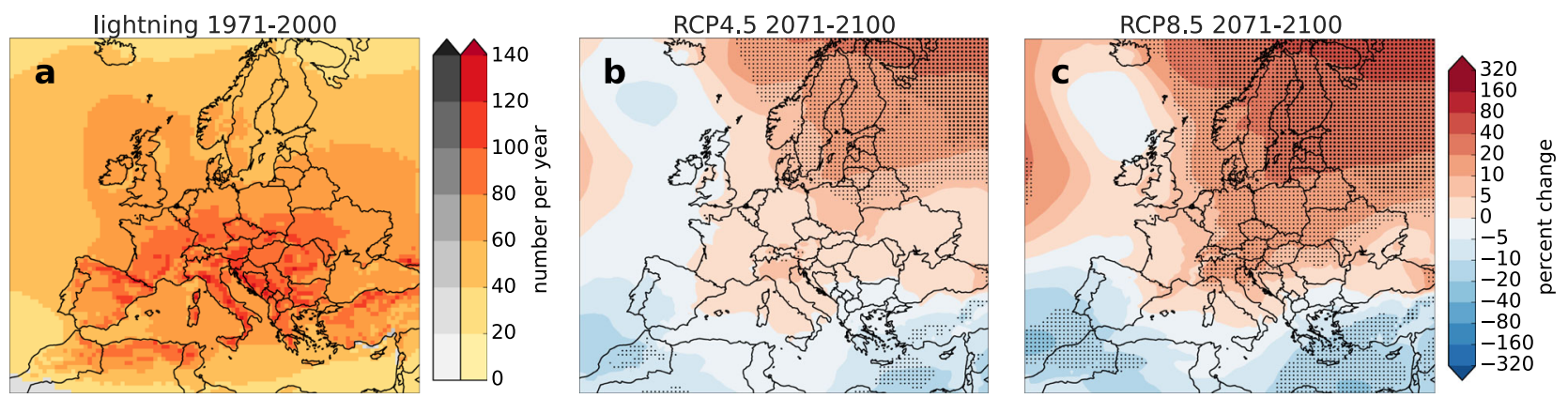

Fig. 1 Simulated annual 6-hourly periods with lightning in a the historical period (1971-2000) and percentage of change at the end of the century (2071-2100) in the b RCP4.5 and c RCP8.5 scenarios. Trends in b, c are called (very) robust where the change is larger than (twice) the initial standard deviation of the model ensemble. (Very) robust changes are indicated by (large) black dots. Areas where models already diverge greatly for the historical period are displayed in gray (see the "Methods" section for details)
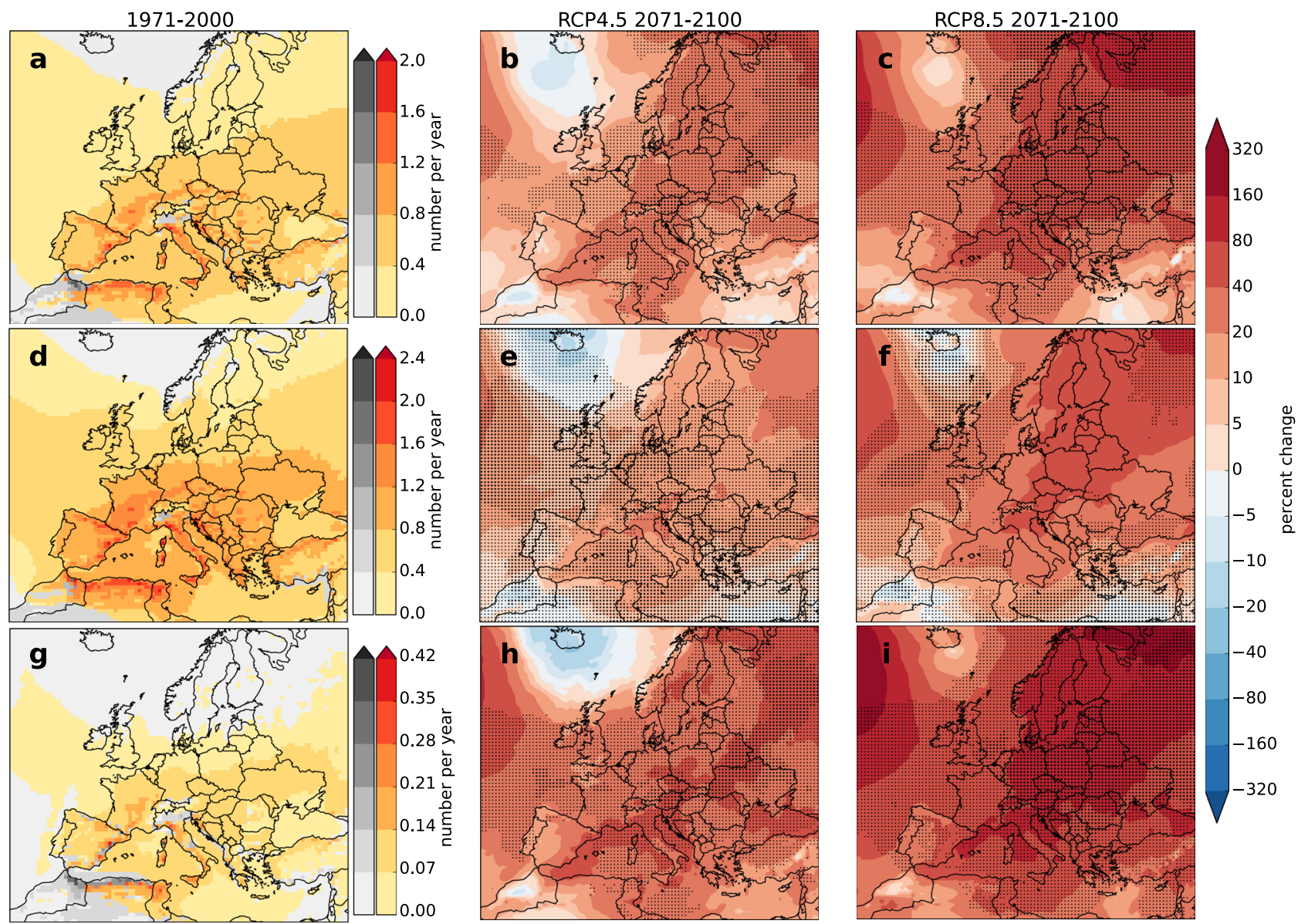

Fig. 2 As in Fig. 1, but for a-c hail $\geq 2 \mathrm{~cm}$, d-f wind gusts $\geq 25 \mathrm{~m} / \mathrm{s}$, and $\mathbf{g}-\mathbf{i}$ hail $\geq 5 \mathrm{~cm}$

2071-2100, a strong and robust relative increase is expected across northern and eastern Europe (of $>20 \%$ in the RCP8.5 scenario), as well as a smaller increase in central Europe (Fig. 1b, c). A decrease in lightning frequency is projected across southwestern and southeastern Europe and adjacent portions of the Middle East. All changes are greatest and most robust in the RCP8.5 climate scenario.

The occurrences of large hail ( $\geq 2 \mathrm{~cm}$ diameter) and of damaging convective winds are found to increase more strongly than the occurrence of lightning, with a robust upward trend across most regions (Fig. 2a-c). Large hail is projected to become $40-80 \%$ more likely across central and eastern Europe in the RCP8.5 scenario by the end of the century. The projected changes in wind events are similar to projected changes in hail events, but smaller (Fig. 2d-f). In addition, we considered the evolution of hail with diameters of $\geq 5 \mathrm{~cm}$, since these cause the most severe damage. Such hail, which can damage crops, cars, and roofs of buildings, is robustly projected to become more likely across most of Europe, with a doubling possible in parts of central and northeastern Europe in the RCP8.5 run (Fig. 2g-i).

The projected greater increases in hazards than in lightning over many regions imply that a greater fraction of thunderstorms will produce severe weather. Indeed, the severe weather efficiency of storms is predicted to increase in all regions and in all climate scenarios until 2100. For instance, in central Europe, the percentage of lightning cases with hail $\geq 5 \mathrm{~cm}$ initially ranges 

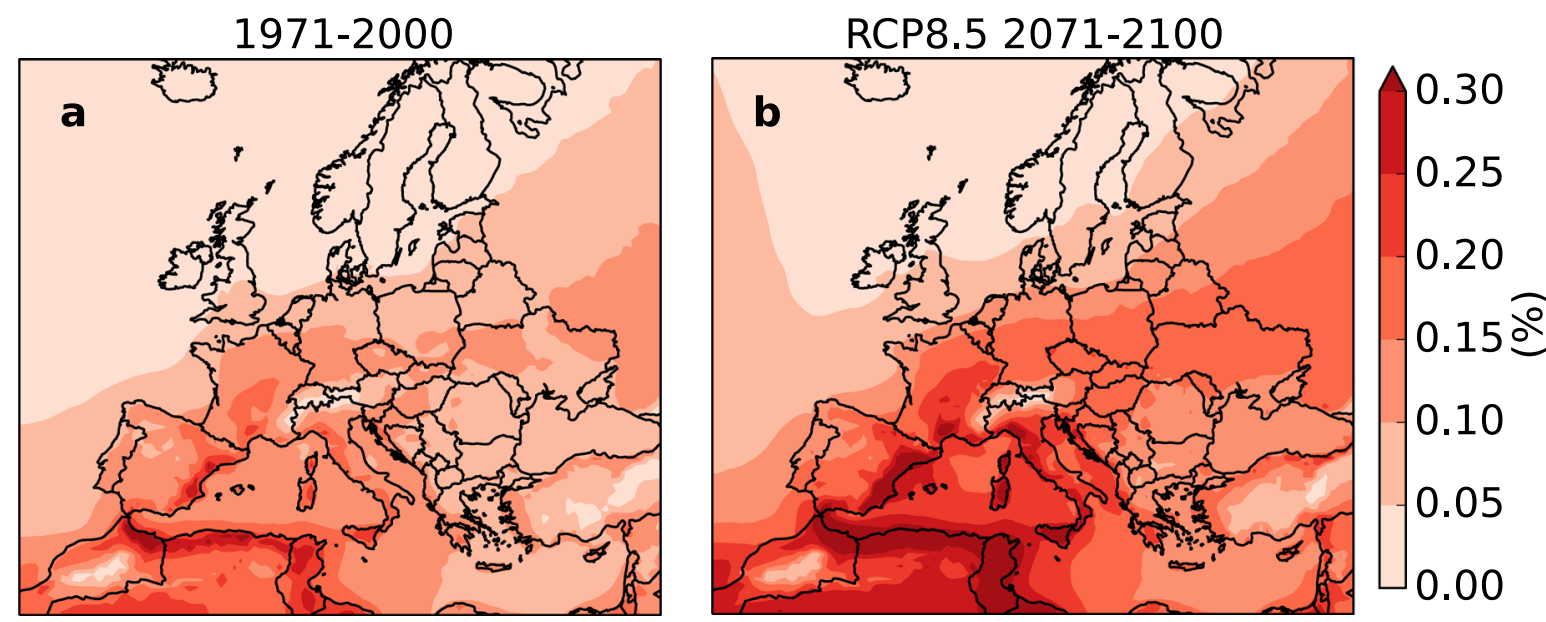

Fig. 3 Percentage of lightning cases with hail $\geq 5 \mathrm{~cm}$ for a 1971-2000 and b RCP8.5 2071-2100

between $0.05 \%$ and $0.15 \%$ (Fig. 3a) and increases to $>0.25 \%$ (Fig. $3 \mathrm{~b}$ ) at the end of the $21 \mathrm{st}$ century for the most aggressive climate scenario (RCP8.5). Similarly, over the western Mediterranean, this fraction is expected to increase from around $0.15 \%$ to $>0.20 \%$.

We attribute the projected changes to physical changes in the atmosphere. To do so, we turn to the predictor parameters used in the additive regression models, which include the Lifted Index (LI), representing convective instability, the average relative humidity between 850 and $500 \mathrm{mb}(\mathrm{RH})$, and the bulk wind shear between $10 \mathrm{~m}$ above ground and the $500 \mathrm{mb}$ pressure level (deep-layer shear (DLS)). First, it is found that the $5 \%$ most unstable weather situations (Fig. 4a, b) are expected to become more unstable, which is the primary explanation for the increase in thunderstorms, hail storms, and severe wind gusts. This increased instability ultimately results from higher low-level humidity. ${ }^{8}$ Second, the simultaneously falling mid-tropospheric relative humidity suppresses convective storms across the southern half of Europe (Fig. 4c, d), primarily by promoting the entrainment of dry air into storm updrafts and thus preventing the development of small convective clouds into thunderstorms. ${ }^{6,7,14}$ This mid-level drying is likely related to a northward shift of the downward branch of the Hadley-cell circulation. ${ }^{15}$ Across northern Europe, however, small increases of mid-level relative humidity, and thereby a weakening of this inhibiting effect on storm formation, can be detected. Lastly, the projected changes in wind shear may be somewhat counter-intuitive. It has been suggested that the polar jet stream will meander more in response to the reduced temperature contrast between the North Pole and the equator, ${ }^{16}$ related to Arctic amplification, i.e., the positive feedback loop caused by the loss of sea-ice in the $\operatorname{Arctic}^{17}$ and other mechanisms. However, the projections show that wind shear in unstable situations does not decrease (Fig. 4c, d), and even increases robustly across parts of central and eastern Europe. A possible explanation is that shear is intensified in major convective situations across western and central Europe as a large southerly mid-level jet develops on the western flank of hot air advected northward. ${ }^{18}$ This air may originate from the Sahara Desert, the Iberian Peninsula, or warm as it subsides in the lee of the Alps and is not influenced much by the northern hemispheric meridional temperature gradient. The combined result of these effects results in a slight amplification of the probability that convective storms develop into well-organized convective modes.

\section{METHODS}

We used an ensemble of 14 regional climate models to assess the changes in frequency of thunderstorm-related hazards across Europe until the end of the 21 st century. The hazards we address are too local and short-lived to be resolved by the climate models. We therefore developed the AR$\mathrm{CHaMo}^{7}$, a set of statistical models to represent the occurrence of smallscale hazards in climate models and reanalysis data.

The AR-CHaMo models were developed using ERA-Interim reanalysis data, ${ }^{19}$ EUCLID ${ }^{20}$ lightning data, and ESWD ${ }^{21}$ hazard reports across central Europe for the 2008-2016 period and have been tested on equivalent data for the United States. ${ }^{22}$ From the ERA-Interim reanalysis data, parameters representing atmospheric instability (LI), mid-tropospheric humidity $(\mathrm{RH})$, and deep-layer bulk wind shear (DLS) (see Table S1) act as predictors for the models that have been fitted to the observed occurrence of lightning and to the hazards wind and hail. The additive logistic regression models provide a continuous probability field even for parameter combinations that occurred rarely in the training data set. By design, the probability for lightning $\mathrm{P}$ (storm) occurrence and the conditional probability for the occurrence of hail or wind given that lightning occurs $\mathrm{P}$ (hazard|storm) have been treated as two separate factors (Fig. S1) that have been modeled individually. The probability of a severe hazard is computed as the product of these factors. More details about the methodology of AR$\mathrm{CHaMo}$ are provided in ref. ${ }^{7}$.

EURO-CORDEX is the European branch of the international CORDEX (Coordinated Downscaling Experiment) initiative, an internationally coordinated framework for the production of improved regional climate change projections for all land regions world-wide ${ }^{12}$ sponsored by the World Climate Research Program. The EURO-CORDEX simulations in this study have a horizontal resolution of $0.44^{\circ}$ on a rotated grid, which is approximately $50 \mathrm{~km}$, and the temporal resolution corresponds to $6 \mathrm{~h}(00$ UTC, 06 UTC, 12 UTC, and 18 UTC). Each simulation was driven by global climate simulations from the CMIP5 (Coupled Model Intercomparison Project Phase 5). They are based on greenhouse gas emission scenarios called RCPs (Representative Concentration Pathways) and correspond to stabilization of radiative forcing after the $21 \mathrm{st}$ century at $4.5 \mathrm{~W} \mathrm{~m}^{-2}$ (RCP4.5) and rising radiative forcing exceeding $8.5 \mathrm{~W} \mathrm{~m}^{-2}$ at the end of 21 st century relative to preindustrial levels (RCP8.5). ${ }^{13,23,24}$ Two future 30year time periods, 2021-2050 and 2071-2100 have been considered for each of the two RCP scenarios. They were compared to historical control runs $(\mathrm{H})$ from 1971 to 2000 . To compute the expected annual number of events in a given grid box, the individual probabilities of hazard occurrence in each 6-hourly period within that year were summed. The simulations used in this study are listed in Table S2.

Four different regional climate models were driven by multiple global climate models at different research centers as summarized in Table S2. Additional details on EURO-CORDEX model standards are provided in ref. ${ }^{25}$. For each of the 14 ensemble members, time periods, and RCP scenarios, the predictor parameters were calculated, and subsequently, the AR-CHaMo models for lightning, hail, and wind were applied, resulting in probabilities for lightning, hail, or wind in each 6-h interval and grid cell.

Inter-model and seasonal variability

The predicted changes for each model in a region in central Europe illustrate the level of consistency between individual models (Fig. S2). Relative to the historical period, the spread increases for the 2021-2050 time period and before decreasing somewhat until 2100 in the 
Historical 1971-2000
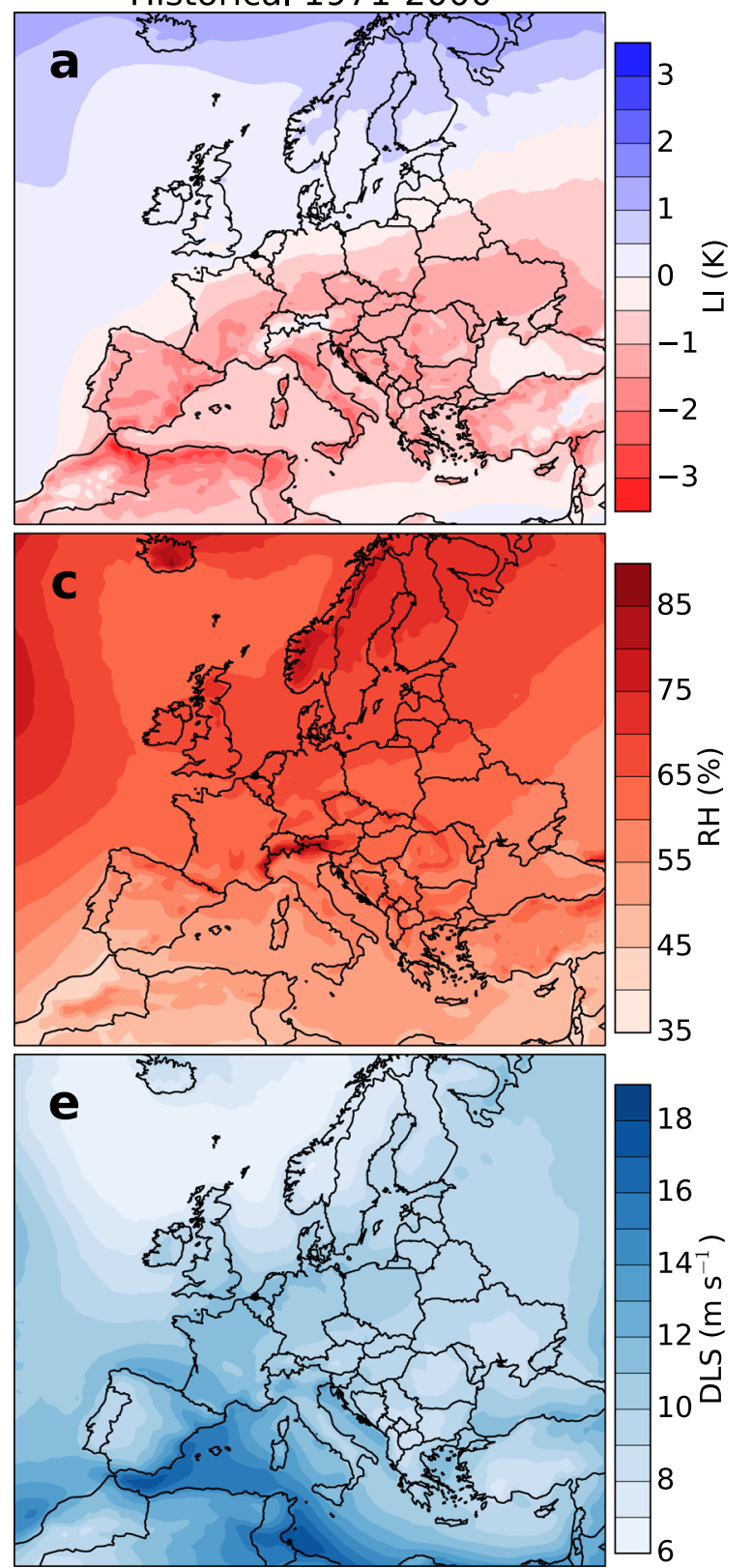
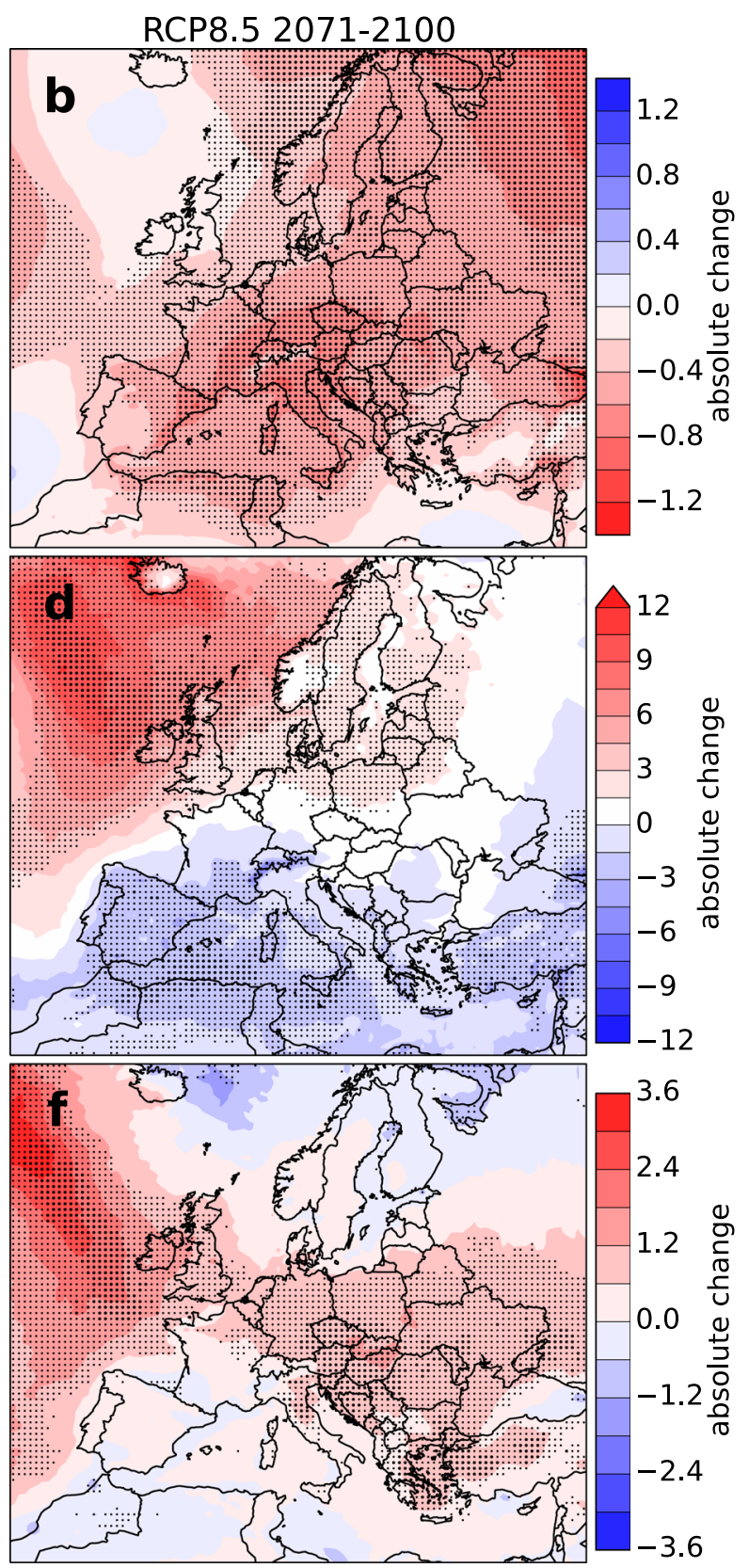

Fig. 4 Euro-CORDEX ensemble mean for a the fifth percentile of Lifted Index (LI) (K) and $\mathbf{b}$ its absolute change for the RCP8.5 scenario and the 2071-2100 time period. c The median of relative humidity (\%) for $\mathrm{LI}<0 \mathrm{~K}$ and $\mathbf{d}$ its absolute change for RCP8.5. e The median of deep-layer shear $\left(\mathrm{m} \mathrm{s}^{-1}\right)$ for $\mathrm{LI}<0 \mathrm{~K}$ and $\mathbf{f}$ its absolute change for RCP8.5

RCP4.5 scenario, while for RCP8.5, the spread among the members continues to increase toward the end of the century.

In the RCP8.5 scenario, all model members predict relative changes in lightning frequency between $-18 \%$ and $+20 \%$ until 2100 , i.e., there is no agreement on the sign of the change. A higher agreement on the direction of change for RCP8.5 is found for wind and hail, where all models predict an increase until the end of the century, even though some do not predict initially (Fig. S2d, f, h). The spread is large, though, as relative increases, e.g., for hail, are between $20 \%$ and $80 \%$, so that the most aggressive model predicts an increase four-fold that of the least aggressive model (Fig. S2d). The predicted relative changes for hail $\geq 5 \mathrm{~cm}$ (Fig. S2e, f) are much higher than those of hail $\geq 2 \mathrm{~cm}$ and range from $+47 \%$ to $+139 \%$. This stresses how important it is not to rely on the prediction of one particular model. For wind, the changes are similar in magnitude to those of hail $\geq 2 \mathrm{~cm}$ (Fig. $\mathrm{S} 2 \mathrm{~g}, \mathrm{~h})$. Some models are consistently on the low end of the envelope (RACMO-ECEarth, RCA-CSIRO), whereas others, particularly RCA-MIROC, is at the upper end.
A pan-European impression of inter-model variability is provided in Figs. S3-S6 for RCP8.5 and 2071-2100. Regarding lightning cases, there is a high variability among the ensemble member throughout Europe. Indeed, until 2100 RCA-CSIRO predicts a decrease in lightning across central Europe, while RCA-MIROC predicts an increase (Fig. S3). Considering hail or wind, the majority of ensemble members predict a strong increase throughout Europe, but in southwestern Europe the direction of change of these hazards varies. For instance, the changes in RCA-IPSL and RCA-MIROC for hail and wind have opposite signs across Spain (Figs. S4-6). It can be seen that important differences exist both among simulations with the same global CMIP5 model and between those that used the same global but different regional models.

Considering the seasonality of predicted lighting and hazard occurrences, the highest frequency for the historical time period in central and western Europe is simulated in boreal summer (JJA) (for lightning see Fig. S9 and for hail $5 \mathrm{~cm}$ see Fig. S11). Relative changes for the time period 2071-2100 and RCP8.5 compared to the historical period are simulated for 
all seasons, but its robustness and number differs throughout the year (Fig. S10 for lightning and Fig. S12 for hail $5 \mathrm{~cm}$ ).

\section{DATA AVAILABILITY}

The data that supports the findings in this study are EURO-CORDEX ${ }^{12}$ climate simulations, which were provided from several research centers and $\mathrm{AR}-\mathrm{CHaMo}^{7}$ models. The data sets generated during and/or analyzed during the current study are available from https://github.com/araedler/Raedler_et_al_2019. Additional data are available from the corresponding author on reasonable request.

\section{CODE AVAILABILITY}

The python computer code which was used to generate the results and figures for this study are available from https://github.com/araedler/Raedler_et_al_2019. Additional code is available from the corresponding author on reasonable request.

\section{ACKNOWLEDGEMENTS}

We are thankful to the various support of all research centers that provided the EURO-CORDEX climate simulations. We would like to thank Grigory Nikulin, Andreas F. Prein, Erik Van Meijgaard, Rowan Fealy, Daniela Jacob, and Claas Teichmann for providing the EURO-CORDEX simulations. A.T.R.'s, P.H.G.'s, T.P.'s and E.F.'s contribution was carried out within the project ARCS (Analysis of changes in the Risk of severe Convective Storms in Europe), which is funded by Munich Re and by the Federal Ministry of Education and Research (BMBF) under grant 01LP1525A.

\section{AUTHOR CONTRIBUTIONS}

A.T.R. and P.H.G. conceived the study. A.T.R. applied the statistical models to the climate simulations and analyzed the results with the support of R.S. and E.B. and prepared the figures. T.P. collected the EURO-CORDEX data from their respective modeling centers. A.T.R and P.H.G. wrote the manuscript.

\section{ADDITIONAL INFORMATION}

Supplementary information accompanies the paper on the npj Climate and Atmospheric Science website (https://doi.org/10.1038/s41612-019-0083-7).

Competing interests: The authors declare no competing interests.

Publisher's note: Springer Nature remains neutral with regard to jurisdictional claims in published maps and institutional affiliations.

\section{REFERENCES}

1. Hoeppe, P. Trends in weather related disasters - consequences for insurers and society. Weather Clim. Extrem. 11, 70-79 (2016).

2. Fujita, T. T. Manual of Downburst Identification for Project NIMROD. SMRP Research Paper 117, Univ. Chicago, 104 pp [NTIS N78-30771/1GI.] (1978)

3. Gallus, W. A. Jr., Snook, N. A. \& Johnson, E. V. Spring and summer severe weather reports over the Midwest as a function of convective mode: a preliminary study. Weather Forecast 23, 101-113 (2008).

4. Smith, B. T., Thompson, R. L., Grams, J. S., Broyles, C. \& Brooks, H. E. Convective modes for significant severe thunderstorms in the contiguous United States. Part I: Storm classification and climatology. Weather Forecast 27, 1114-1135 (2012).

5. Petoukhov, V. et al. Role of quasiresonant planetary wave dynamics in recent boreal spring-to-autumn extreme events. Proc. Natl Acad. Sci. 113, 6862-6867 (2016).

6. Coumou, D., Di Capua, G., Vavrus, S., Wang, L. \& Wang, S. The influence of Arctic amplification on mid-latitude summer circulation. Nat. Commun. 9, 2959 (2018).
7. Rädler, A. T., Groenemeijer, P., Faust, E. \& Sausen, R. Detecting severe weather trends using an additive regressive convective hazard model (AR-CHaMo). J. Appl. Meteor. Climatol. 57, 569-587 (2018).

8. Púčik, T. et al. Future changes in European severe convection environments in a regional climate model ensemble. J. Clim. 30, 6771-6794 (2017).

9. Diffenbaugh, N. S., Scherer, M. \& Trapp, R. J. Robust increases in severe thunderstorm environments in response to greenhouse forcing. Proc. Natl Acad. Sci. USA 110, 16361-16366 (2013).

10. Seeley, J. T. \& Romps, D. M. The effect of global warming on severe thunderstorms in the United States. J. Clim. 28, 2443-2458 (2015).

11. Allen, J. T., Karoly, D. J. \& Walsh, K. J. Future Australian severe thunderstorm environments. Part II: The influence of a strongly warming climate on convective environments. J. Clim. 27, 3848-3868 (2014).

12. Jacob, D. et al. EURO-CORDEX: new high-resolution climate change projections for European impact research. Reg. Environ. Chang. 14, 563-578 (2014).

13. Moss, R. H., et al. Towards New Scenarios for Analysis of Emissions, Climate Change, Impacts, and Response Strategies. Technical Summary (Intergovernmental Panel on Climate Change, Geneva, 2008) 25 pp.

14. Derbyshire, S. H. et al. Sensitivity of moist convection to environmental humidity. Q. J. R. Meteorol. Soc. 130, 3055-3079 (2004).

15. Lu, J., Vecchi, G. A. \& Reichler, T. Expansion of the Hadley cell under global warming. Geophys. Res. Lett. 34, L06805 (2007).

16. Harvey, B. J., Shaffrey, L. C. \& Woollings, T. J. Equator-to-pole temperature differences and the extra-tropical storm track responses of the CMIP5 climate models. Clim. Dyn. 43, 1171-1182 (2013).

17. Screen, J. A. \& Simmonds, I. The central role of diminishing sea ice in recent Arctic temperature amplification. Nature 464, 1334 (2010).

18. van Delden, A. The synoptic setting of thunderstorms in western Europe. Atmos. Res. 56.1-4, 89-110 (2001).

19. Dee, D. et al. The ERA-Interim reanalysis: conguration and performance of the data assimilation system. Q. J. R. Meteorol. Soc. 137, 553-597 (2011).

20. Schulz, W. et al. The European lightning location system EUCLID-Part 1: Performance analysis and validation. Nat. Hazards Earth Syst. Sci. 16, 595-605 (2016).

21. Dotzek, N., Groenemeijer, P., Feuerstein, B. \& Holzer, A. M. Overview of ESSL's severe convective storms research using the European Severe Weather Database ESWD. Atmos. Res. 93, 575-586 (2009).

22. Rädler, A. T., Púčik, T., P. Groenemeijer \& Tijssen, L., Comparison between European and US severe convective weather environments, In 9th European on Severe Storms. Pula, Croatia, Retrieved from https://meetingorganizer.copernicus. org/ECSS2017/ECSS2017-193.pdf, (2017)

23. Nakicenovic, N. et al. Special Report on Emissions Scenarios: a Special Report of Working Group III of the Intergovernmental Panel on Climate Change (Cambridge University Press, Cambridge, 2000)

24. Moss, R. H. et al. The next generation of scenarios for climate change research and assessment. Nature 463, 747-756 (2010).

25. Kotlarski, S. et al. Regional climate modeling on European scales: a joint standard evaluation of the EURO-CORDEX RCM ensemble. Geosci. Model Dev. 7, 1297-1333 (2014).

\begin{abstract}
Open Access This article is licensed under a Creative Commons

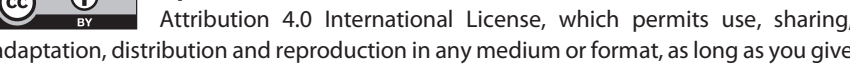
appropriate credit to the original author(s) and the source, provide a link to the Creative Commons license, and indicate if changes were made. The images or other third party material in this article are included in the article's Creative Commons license, unless indicated otherwise in a credit line to the material. If material is not included in the article's Creative Commons license and your intended use is not permitted by statutory regulation or exceeds the permitted use, you will need to obtain permission directly from the copyright holder. To view a copy of this license, visit http://creativecommons. org/licenses/by/4.0/.
\end{abstract}

(c) The Author(s) 2019 